\title{
INTRODUCTION TO UROLOGY
}

\author{
Chris Dawson, Hugh Whitfield
}

\section{Scope of urology}

\author{
- Urodynamic disorders \\ - Oncology \\ - Stone disease \\ - Reconstruction \\ - Paediatric urology \\ - Andrology
}

Subspecialties in urology

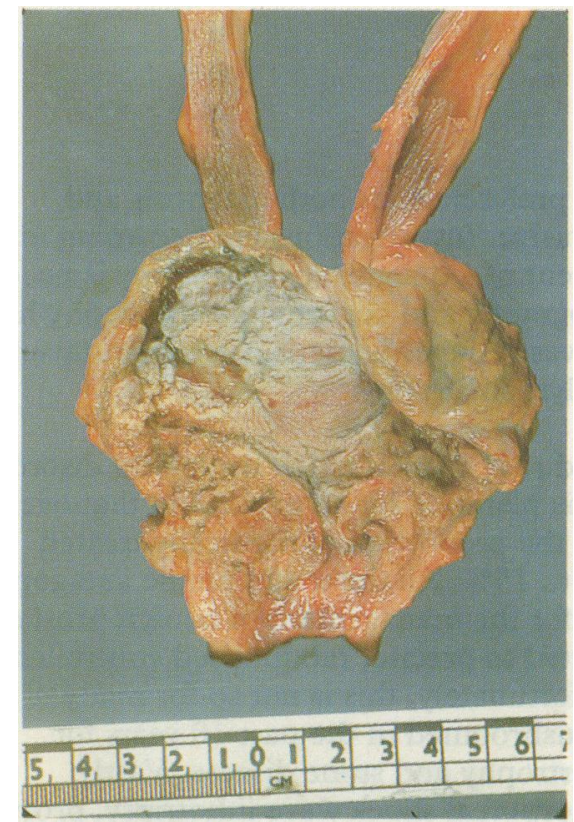

Excised specimen of cancerous bladder showing large tumour mass.
Urological surgery was one of the last surgical disciplines to become recognised as a separate specialty from general surgery in terms of training and practice. Urological disorders account for about one third of all surgical admissions to hospital. Such disorders are common in the community, and though few are life threatening, many may have a profound effect on the quality of life.

It is not surprising that specialisation within urology, as in all other medical and surgical disciplines, provides the best quality of care. The confidential inquiry into perioperative deaths (CEPOD) highlighted that prostatectomy, the operation performed most frequently by urologists, is associated with a significantly lower mortality and morbidity when performed by surgeons who carry out more than 50 such procedures a year. All urologists provide care to some extent in all the subspecialties of urology, but most will concentrate on one or two as specific interests. Urological surgical specialisation, however, only becomes fully effective with specialised urological nursing.

\section{Urodynamic disorders}

Problems of bladder outflow obstruction secondary to benign prostatic hypertrophy constitute about a third of urological practice. Other urodynamic disorders occur in patients with neurological disorders of many kinds. The management of patients with urinary incontinence is also included under this heading.

\section{Oncology}

Bladder tumours and prostate cancer are the two commonest malignant diseases presenting to urologists. Most urology departments run a haematuria service as many studies confirm the importance of investigating haematuria urgently. Prostate cancer is now being diagnosed at an earlier stage and more often since the advent of prostatic specific antigen and transrectal, ultrasound guided biopsies of the prostate. All urologists can treat patients with a bladder tumour or prostate cancer, but more complex and advanced disease requiring major surgery is best dealt with by a cancer centre.

\section{Stone disease}

The prevalence of stone disease in the United Kingdom (3\%) is much lower than in many other developed and developing countries. The need for expensive, high technology equipment dictates that patients who need intervention for their stones are best treated in stone centres, of which there should be one or two per health region. 


\section{Reconstruction}

\section{Andrology}

- Impotence and infertility are two quite separate parts of andrology

- Advances in diagnostic and therapeutic techniques in both areas offer a chance of notable improvement in the quality of life for patients
Reconstructive urological procedures include surgery for congenital malformations, though many of these are best treated by paediatric rather than adult urologists. Complex urethral strictures need special expertise. There is an increasing tendency to avoid urinary diversion in favour of a reconstructive procedure - to provide a continent neobladder - in patients who have had a cystectomy or who have intractable incontinence secondary to bladder neuropathy or congenital malformation. Such procedures are usually carried out by those who specialise in reconstructive urology.

\section{Allied disciplines}

- Urologists overlap with other specialists

- Nephrologists, urologists, and primary health care physicians may manage all patients with urinary infections

- Nephrologists call on urologists to manage patients in acute or chronic renal failure due to obstruction

- Surgical aspects of renal replacement may be provided by urologists or transplant surgeons

- In the field of urinary incontinence urologists can provide expert care to both men and women. Urologically oriented gynaecologists-

urogynaecologists-also offer such care to incontinent women

\section{Paediatric urology}

Paediatric urology, which was pioneered in Britain, encompasses the management of congenital malformation such as hypospadias, bladder exstrophy, posterior urethral valves, vesicoureteric reflux, pelviureteric junction obstruction, and surgery for the urological malignant diseases of infancy and childhood, such as Wilms's tumour and rhabdomyosarcoma of the bladder. Diagnosis of urological conditions in utero is now possible, and these need the expertise and opinion of the paediatric urologist.

\section{Philosophy of urology}

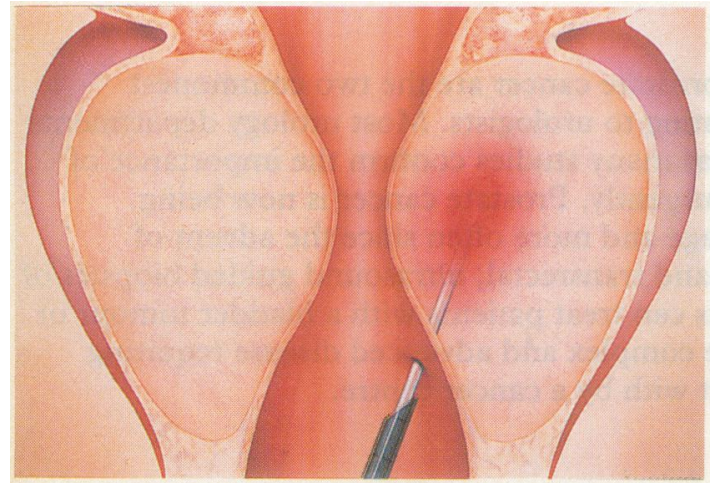

Interstitial laser treatment with indigo diode laser.
There is an ever increasing preference for both diagnosis and treatment to be minimally invasive. Investigations are becoming more sophisticated, and the equivalent of a diagnostic laparotomy is needed very rarely, if at all. Ultrasonography and computed tomography have replaced many of the more invasive investigations, such as intravenous urography, angiography, and lymphography.

New drugs have been introduced to treat many urological disorders. The pharmaceutical industry is planning for an expansion that over the next 10 years will see a rise in the proportion of medically treated urological disorders from $3 \%$ to $15 \%$. All the $\alpha$ adrenergic antagonists and a 5- $\alpha$ reductase inhibitor for the management of benign prostatic hypertrophy have been subjected to precise, randomised controlled prospective clinical trials. Unfortunately, this is not so for many of the new technologies that have mushroomed in the past 10 years for treating benign prostatic hypertrophy and stone disease. Vastly expensive machines for extracorporeal shock wave lithotripsy, prostate hyperthermia and thermotherapy, laser ablation of the prostate, and cryosurgery of the prostate have been introduced before the results of proper clinical evaluation have been available. The same criticism can be made of other treatments for benign prostatic hypertrophy--such as stents, balloon dilatation, and prostate vaporisation. Urologists must take much of the responsibility for such hasty and sometimes ill conceived therapeutic interventions, which have been proved subsequently to be of little if any value. Active cooperation with the new Medical Devices Agency should help to make amends for past mistakes. 


\begin{tabular}{|lc|}
\hline \multicolumn{2}{|l|}{ Ratio of urologists to population } \\
Belgium & $1: 40000$ \\
Luxembourg & $1: 27000$ \\
Netherlands & $1: 56000$ \\
Portugal & $1: 40000$ \\
Spain & $1: 35000$ \\
Britain & $1: 148000$ \\
United States & $1: 29000$ \\
Czech Republic & $1: 29000$ \\
\hline
\end{tabular}

In an aging population the number of patients presenting with urological problems who can benefit from treatment rises, particularly as the morbidity with intervention falls. There is, however, an acute shortage of fully trained urological surgeons in Britain. Several factors account for this. The new generation of general surgeons is not trained in urology, and the number of trainees needed to fill the anticipated number of consultant posts was greatly underestimated by the Department of Health Joint Planning Advisory Committee 10 years ago. The recommendation by the British Association of Urological Surgeons is that there should be one urologist per 100000 people, which compares poorly with other countries. The association's figure is far from realised, with the current ratio being 1:148 000. This hides pockets of very great underprovision. The temptation for trusts to appoint clinical assistants, staff grade urologists, and inadequately trained locums as substantive consultants will lead to a second rate quality of care.

\section{Shared care and clinical nurse practitioners}

- Protocols agreed between general practitioners and urologists can minimise the number of times patients have to visit hospitals

- Integration of community based care in a urology department ensures that patients who are discharged or who need a urological opinion can be readily seen in the appropriate place

- Such arrangements are particularly helpful in managing patients with urinary incontinence

- Nurses working in urology now perform tasks previously done only by doctors

- Patients can receive a high quality of care that is supervised by suitably trained nurses

A solution to the problem exists. Urological inpatient care should be provided only on sites that serve an area with a population of about 750000 . The concentration of six or more urological consultants in one inpatient centre would ensure that all urological subspecialties are available. The number of urologists in training at such a centre would enable 24 hour urological cover to be provided. Equally important, the concentration of inpatient care would justify dedicated urological nursing in theatres and wards. Outpatient and day case procedures can be provided much more widely than inpatient care. Very specialised treatment could be offered at tertiary referral centres, which would usually be in teaching hospitals.

The illustration of the cancerous bladder was supplied by the Science Photo Library.
The ABC of Urology is edited by Chris Dawson, a senior registrar in urology at the Edith Cavell Hospital, Peterborough, and Hugh Whitfield, a consultant urologist at the Central Middlesex Hospital and the Institute of Urology and Nephrology, London.

\section{A LESSON CONFIRMED}

\section{Cocaine and adrenaline paste: a fatal combination?}

The Lesson of the Week "Cocaine and adrenaline paste: a fatal combination" calls to mind my own experience of this combination of drugs being used intranasally. ${ }^{1}$ In the early 1970 s the neurosurgeon with whom I worked, the late Mr Huw Griffith, adopted the transnasal approach for hypophysectomy. Immediately after induction of anaesthesia both nostrils were packed with half inch ribbon gauze soaked in a mixture of $5 \mathrm{ml}$ of $5 \%$ cocaine and $5 \mathrm{ml}$ of 1:2000 adrenaline. I inserted the ribbon gauze and this procedure was followed by radial artery cannulation for monitoring the pulse and blood pressure throughout the surgery.

It was soon observed that an uncomfortable proportion of patients developed a fast tachycardia and varying degrees of hypertension shortly after insertion of the pack. After a while I omitted the adrenaline from the mixture without telling the surgeon. The episodes of tachycardia and hypertension ceased.

I questioned Mr Griffith about the quality of the operating conditions. Having established that the conditions remained perfectly satisfactory $I$ then confessed. $\mathrm{Mr}$ Griffith agreed that there was no justification for reverting to the previously used mixture, and, in due course, even the ribbon gauze was abandoned in favour of using a simple $5 \%$ cocaine nasal spray. No further problems were encountered, and it is probable that we were lucky that no more serious untoward effects were seen in the early years of using the cocaine and adrenaline mixture.-JOHN ZORAB is a consultant anaesthetist in Bristol

1 Nicholson KEA, Rogers JEG. Cocaine and adrenaline paste: a fatal combination? BMF 1995;311:250-1.

We welcome filler articles of up to 600 words on topics such as $A$ memorable patient, $A$ paper that changed my practice, My most unfortunate mistake, or any other piece conveying instruction, pathos, or humour. If possible the article should be supplied on a disk. 